Article

\title{
Economic Distance to Gather Agricultural Residues from the Field to the Integrated Biomass Logistic Centre: A Spanish Case-Study
}

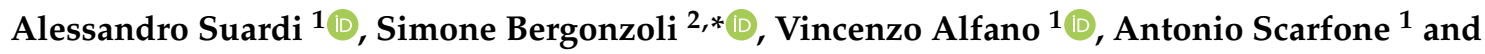 \\ Luigi Pari ${ }^{1}$ (D) \\ 1 Council for Agricultural Research and Economics, Research Center for Engineering and Agro-Food \\ Processing (CREA-IT), Via della Pascolare, 16, 00015 Monterotondo, Italy \\ 2 Council for Agricultural Research and Economics, Research Center for Engineering and Agro-Food \\ Processing (CREA-IT), Via Milano, 43, 24047 Treviglio, Italy \\ * Correspondence: simone.bergonzoli@crea.gov.it
}

Received: 12 July 2019; Accepted: 7 August 2019; Published: 10 August 2019

\begin{abstract}
A big amount of agricultural residues are generated from crop production and partially remain in the field after harvest. Removing the excess of residues after crop harvesting can increase farmer income, providing feedstock that could be used for industrial and energy purposes. The costs for collection and transport of straw and stalks are site- and region-specific and depend on the availability of agricultural residue and on how much of the residue is removed from any specific field or location. If the biomass is baled then it is required to upload the bales on a trailer, transport and unload all the baled biomass to the storage center. On the other hand, if a self-loading wagon is used the loose biomass collected, it must be unloaded every time the wagon is completely full. The distance and the harvesting system used influence the costs and should be analytically studied to avoid turning a possible profit into a disadvantageous business. The research represents a real case study to evaluate, which is the maximum distance to the biomass logistic center from which it is more economically convenient to gather the wheat and corn residues in bales instead of using a self-loading wagon. The results show a lower harvesting unitary cost for the self-loading forage wagon respect to the baling system. Although the study showed delivery distances over $11.4 \mathrm{~km}$ for wheat straw and $16.0 \mathrm{~km}$ for maize stalks, the use of the self-loading forage wagon is no longer convenient, and baling is the preferred harvesting system.
\end{abstract}

Keywords: agricultural residue; maize stalk; cereal straw; harvesting; baler; self-loading wagon; cost analysis; transport cost

\section{Introduction}

The European Union Directive on the promotion of the use of energy from renewable sources (RED) includes a binding target of a $20 \%$ share of renewable energy in energy consumption in EU by 2020 [1,2]. Bioenergy sector, as possible solution to this issue, has attracted much attention in last years because feedstocks can be suitable surrogates for traditional energy production systems which are finite, non-renewable, and cause of environmental concerns [3]. It is now foreseen that biomass could provide around two-thirds of the renewable energy share in 2020 according to scenarios. The bioenergy value chain requires the delivery of the biomass feedstock from the production sites to the utilization centers. Along this path, the biomass passes through facilities and processes that composed the so-called biomass supply chain. Each step of the supply chain needs specific expertise, technology, and operations including biomass production, feedstock transportation, processing, and 
consumption. The design of the supply chain is a fundamental aspect for the improvement of its performance and efficiency [4].

Excluding the forestry sector, agriculture can be a source of biomass for energy purpose either by establishing plantations of bioenergy crops (e.g., rotation forestry, perennial, or annual herbaceous crops) or by removing residue from cropland. Crop residue is defined as the non-edible plant part that is not harvested and left in the soil [5]. The different residues produced by the agricultural sector may contribute to reach the goal defined by renewable energy directives since a big amount of agricultural byproducts are generated from crop production and still remain in the soil after harvesting [6]. While production of energy from crop by product is already a possible initiative, the potential risk of crop residue removal on soil organic carbon (SOC) and soil organic matter (SOM) deserves attention. Studies have highlighted that SOM content is directly related to the amount of residue maintained on the soil [7]. Furthermore, crop residues remaining on the fields are not a waste but provide numerous ecosystem services including SOC sequestration, being a direct source of SOC pool [8]. The availability of crop byproducts is then related to the quantity that can be removed from the soil to maintain its fertility and to other uses as those related to industrial and agricultural sectors. Crop byproducts defend land from erosion, sustain or increase soil organic matter, preserve macro- and micronutrients of the soil, while also supporting water retention capacity [9]. A proper degree of residue removal should be identified on the basis of the quantity that must be maintained in the field to keep soil fertility and avoiding soil impoverishment and erosion [10,11].

The consequences of residue removal rely on the crop, farm management (crop cycle, soil operations, fertilization), site characteristics (e.g., soil type and fertility, soil organic matter, water content, topography and slope, etc.), climate conditions (e.g., wind, precipitation) and harvesting system [12].

The cost of the logistic operations is another aspect that should be taken into consideration when a new agricultural waste for energy value chain is implemented. In fact, it represents one crucial bottleneck in developing the supply chain for biomass feedstock utilization for energy production.

The increasing feedstock request and the sophisticated supply chain highlight the importance of a global management of the biomass procurement system.

Each feedstock supply chain needs different biomass characteristics on the basis of energy requirements trends, energy processing system, use of the energy produced, and the type of the logistic chain [13]. Therefore, the financial barriers as biomass collection, transportation, and processing heavily affect the economic feasibility of crop byproduct utilization [14,15].

One of the most interesting energy feedstocks is stalk, due to its cellulose richness and spread cultivation [16]. Cereal stalk is the non-grain part of the plant (e.g., corn or wheat) that is not collected and remains on the soil, except stubble, husk, leaves, cobs or chaff.

Furthermore, in the EU the main conventional uses of cereal straw (mainly wheat straw) within the agriculture sector are animal feed integration, livestock litter, soil improver, frost prevention for some horticultural product and compost production. Outside the agricultural sector cereal straw is used for thatching, as traditional building materials (fiber boards, insulation material), and for energy (heat, power, fuels) [17].

Instead, corn stalks are usually used for low-value applications like animal feeding and bedding; however, as reported by Kadam (2003), it can also be used for the production of composite product (e.g., particleboard), pulp and paper, or for energy production, either through direct combustion of residues or through microbial conversion of residues to ethanol fuel [18].

Removing the excess amount of residues can reduce the need to till, increase farmer income providing millions of dry tons of feedstock for the production of fuels, chemicals, and materials. However, the assessment of the economic sustainability of the field and transport phases is critical to decide the final use of the biomass and the best harvesting technique to be used for each specific case.

The harvesting of cereal residues is normally carried out by using the haymaking equipment (i.e., rake, baler, etc.), but no attention is often paid on the selection of the machines that better fit to 
the agricultural residues logistic chain or that could reduce the harvesting costs. In fact, sometimes, equipment already available in the farm that is not acquired for the collection of the residues could be used also for this purpose reducing their harvesting costs.

During the European project AGROinLOG [19], the concept of Integrated Biomass Logistic Centre (IBLC) was defined as a "business strategy for agro-industries to take advantage of unexploited synergies in terms of facilities, equipment, and staff capabilities to diversify regular activity both on the input (food and biomass feedstock) and output side (food, biocommodities and intermediate biobased feedstock) thereby enhancing the strength of agro-industries and increasing the added value delivered by those company". In the same project, an important agro-industry of fodder located near Zaragoza (Spain) was chosen as a case study to demonstrate the possible integration of an agricultural residue supply chain to the standard activity carried out by the company. In this particular study, the agricultural equipment usually used for the harvesting of alfa-alfa (Medicago sativa, L.) was used also for the collection of the cereal straw and maize stalks in order to assess the economic feasibility of the harvesting and transportation of biomass from the field to the IBLC.

The costs for collection and transport of straw and stalks are site- and region-specific and depend on the availability of agricultural residue (tons of residue per hectare of land- $\mathrm{Mg} \mathrm{ha}{ }^{-1}$ ) and the amount of the residue that is removed from any specific field or location. If the biomass is baled, then it is required to upload the bales on the trailer and transport and discharge all the baled biomass to the storage center. On the other hand, if a self-loading trailer is used, the loose biomass collected must be discharged every time when the wagon is completely full. The distance from the field to the IBLC where the biomass is stored affects the cost of transportation and should influence the choice of the equipment used.

The objective of this study was to evaluate the performance and to estimate the costs of two different harvesting systems and supplying for wheat straw and corn stalks, in order to define the best method to gather and transport the residual biomass from the field to the storage center according to the distance.

\section{Materials and Methods}

\subsection{Agroindustrial Pascual Sanz SL (APS): Case Study}

The large field tests have been carried out near Agroindustrial Pascual Sanz SL (APS) headquarter (Zaragoza, Spain-41 $38^{\prime} 23.4^{\prime \prime} \mathrm{N} 0^{\circ} 45^{\prime} 6.2^{\prime \prime} \mathrm{W}$ ). The company is dedicated to the production of dehydrated forage in bales or pellet format. The raw material is mainly alfalfa and is purchased in the market from regular traders in bale format (around $10 \%$ of the alfalfa purchased), and from alfalfa farmers through harvesting service; their purchased product is brought to the agro-industry shredded in regular alfalfa trailers (around $90 \%$ of the raw material-100 farmers).

In minor occasions and depending on quality demand of the consumer, they purchase other forage products (like Sudangrass) to be mixed with the alfalfa. Around $50,000 \mathrm{Mg}$ of alfalfa is received from April to November, which is the working season of the plant to make bales (the $85 \%$ of the production) and pellets (the $15 \%$ of the production) for the animal feed market. Transport to consumers is normally arranged by the agro-industry with external companies. The new business line has been conceived to take advantage of the idle period of the equipment in the plant from December to March. During this time, new pellets for two different purposes will be produced: Energy use and bio-composite materials. A production of $6000 \mathrm{Mg} \mathrm{y}^{-1}$ has been considered as the optimal for the company as a first approach, although the maximum capacity is around $10,000 \mathrm{Mg} \mathrm{y}^{-1}$. The raw material for the production of pellets will be cereal straw, maize stalks, and Sudan grass to be purchased to the farmers around. In order to upgrade the quality of the pellet when the goal is to satisfy the energy demands, woodchips will be acquired. The current line is able to process any type of herbaceous products and woodchips with minor modifications of the operation mode or increasing the maintenance, although the capacity of the line will decrease. During the project AGROinLOG, the plant flexibility will be increased by 
enabling the production of new pellets during the current season of inactivity (December to March) with a negligible investment. Furthermore, two additional markets will be tackled with these new products: Bioenergy and bio-composites.

\subsection{Equipment Description}

The tests were performed in Zaragoza (Spain) in July 2017 for the wheat straw harvesting, and in October 2017 for the maize stalks harvesting. During each trial, two harvesting systems were tested and compared, the baling and the self-loading wagon systems (Figure 1). The machines used during the tests are common tractors and equipment used by APS company to harvest alfalfa.

The baling system (HS-A) was composed by a square baler New Holland BB940 (SB) towed by a tractor New Holland T6050 (TR1). With a second tractor John Deere 6420 (TR2) the bales were loaded on a trailer (TL), and a third tractor John Deere 6420 (TR3) was used to transport and download the bales at the storage center.

The self-loading system (HS-B) was composed by a self-loading wagon (SLW) Lacasta mod. Elefant P31L towed by a second tractor New Holland T6050 (TR4). This system was used for both harvesting and transport the products to the storage center. A common protocol was used during tests to collect the primary data for the study.

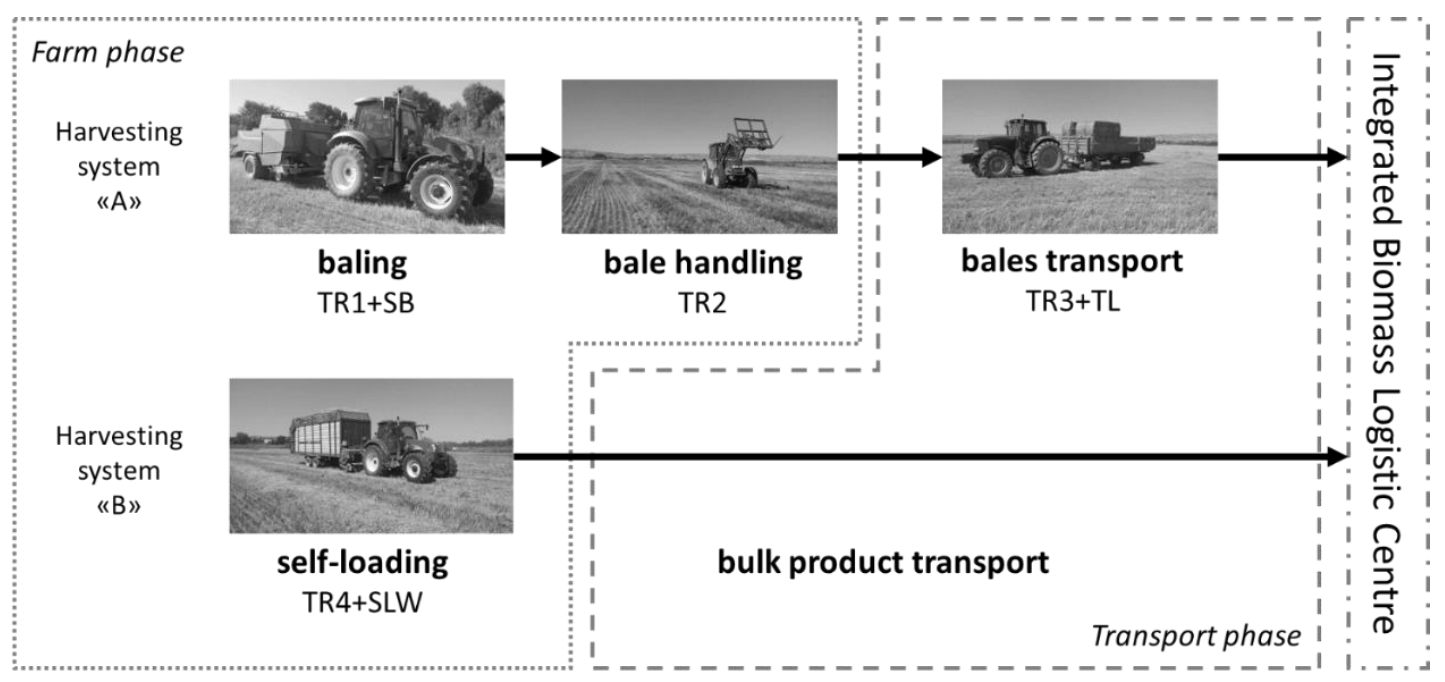

Figure 1. Scheme of the harvesting systems compared during the tests.

\subsection{Dataset and Statistical Analysis}

A split plot experimental design was used for each harvesting test. The fields were divided in three blocks (statistical replications) for each treatment (baling and self-loading tests). The performance analysis was carried out using primary data collected during the tests: These were the working times of the machines used, the bulk densities of the product transported, fuel consumption of the tractors, biomass losses during the harvesting stage and the moisture of the biomass at the IBLC. The secondary data collected were all the economic parameters necessary to carry out the cost analysis of both logistic chains. The cost investments $(€)$, service life (y), resale percentages $(\%)$, annual usages $\left(\mathrm{h} \mathrm{y}^{-1}\right)$, interest rate $(\%)$, the repair factors (\%) and insurance (\%) of the machines, as well as the labor costs were obtained by personal communication and from literature (Table 1). After verifying the normality of the distributions, the data statistical significance were analyzed by ANOVA test [20]. Furthermore, the post-hoc Tukey test $(p<0.05)$ was used to find means that were significantly different from each other.

\subsubsection{Harvesting Data}

Plots with similar area were defined and measured before each harvesting stage. The study of the machine performance was carried out for both the two different machinery chains for each 
residue collected. The work time study was performed according to the CIOSTA (Comité International $\mathrm{d}^{\prime}$ Organisation Scientifique du Travail en Agriculture) methodology and the recommendations from the Italian Society of Agricultural Engineering (A.I.I.A.) 3A R1 [21,22].

Operation time, harvested area, and wheat residues collected per each experimental field were measured during the harvesting tests in order to calculate the following working parameters: Field efficiency $(\%)$, operating speed $\left(\mathrm{m} \mathrm{s}^{-1}\right)$, effective field capacity $\left(\right.$ ha $\left.\mathrm{h}^{-1}\right)$, material capacity $\left(\mathrm{Mg} \mathrm{h}^{-1}\right)$, and yield $\left(\mathrm{Mg} \mathrm{ha}^{-1}\right)$.

Furthermore, fuel consumption was determined through machine tank refilling until full level at the end of each experimental unit (block) using a graduated large cylinder to define the volume of fuel consumed ( $1 \mathrm{ha}^{-1}$ or $1 \mathrm{Mg}^{-1}$ of biomass harvested). Each block was started with the tank completely full. The fuel consumed was proportioned to the exact surface of the block tested to define the fuel consumed per hectare in that experimental unit. The fuel consumption was determined in each block to evaluate if there are statistically significant differences in the consumption (and consequently in operative costs) of one system with respect to the other.

It is important to highlight that, even if the refill method, to measure the fuel consumption is very common and has the advantage of being very easy to apply in the field, and sometimes it is the only method that can be used; its accuracy has been questioned in many studies, especially when the amounts to be measured are minute, and the measurement error is difficult to assess [22].

Working-time study and fuel consumption measurement were performed for all the steps involved: Harvesting, transport, and biomass discharging at the IBLC.

For the treatment " $\mathrm{A}$ " the parameters were measured, according to the above described methodology, also for the operations of uploading of the bales on the trailer.

\subsubsection{Post-Harvesting Data}

The biomass losses were estimated by gathering and weighting the material that was not harvested by the equipment but left on the ground. Three random plots of $10 \mathrm{~m}^{2}$ were chosen per each block, and the biomass present in each plot was collected and weighted with a portable scale. Percentage of losses $(\%)$ were then estimated as the ratio of residue losses $\left(\mathrm{Mg} \mathrm{ha}^{-1}\right)$ to the sum of biomass yield $\left(\mathrm{Mg} \mathrm{ha}^{-1}\right)$ and residue losses $\left(\mathrm{Mg} \mathrm{ha}^{-1}\right)$ for each block. The sum of net biomass yield and biomass losses represented the total biomass yield potential $\left(\mathrm{Mg} \mathrm{ha}^{-1}\right)$.

Furthermore, three samples of cereal residues were randomly collected, weighed to determine the moisture content (\%). The moisture content (MC) of the biomass was determined according to 18134-2:2017 [23]. The bulk density $\left(\mathrm{kg} \mathrm{m}^{-3}\right)$ of the loose biomass was assessed taking 3 samples of biomass for each block, harvested by the self-loading trailer, randomly selected from the biomass discharged by the machine and was measured according to ISO 17828:2015 [24]. The bulk density $\left(\mathrm{kg} \mathrm{m}^{-3}\right)$ of the baled biomass was measured after weighting and calculating the volume of three bales randomly chosen from each block.

\subsubsection{Cost Analysis}

The economic analysis was focused on both ownership and operating costs, according to the parameters measured during the field tests (primary data) or by using standard values provided by the CRPA methodology [25]. Interviews with agroindustry owners and with their usual suppliers have provided further costs items and have validated the data measured during the field tests.

The hourly costs for all the tractors and equipment tested during the harvesting, loading, unloading and transport, were calculated for both logistic chains (baling and self-loading) according to $[25,26]$ (Table 1).

For the HS-A, the hourly costs $\left(\mathrm{H}_{c}\right)$ for transport, the mean load capacity $\left(\mathrm{L}_{c}\right)$, and the mean transport speed $(\mathrm{V})$ were used to calculate the unitary cost $\left(\mathrm{T}_{c}\right)$ per tons of biomass transported per $\mathrm{km}$ $\left(€ \mathrm{~km}^{-1} \mathrm{Mg}^{-1}\right) . \mathrm{L}_{\mathcal{c}}$, and $\mathrm{V}$ were evaluated as the average of three measurements of the transport from the field to the storage center and return $\left(\mathrm{T}_{d}\right)$. 
Table 1. Base-case parameters used for the economic analysis of the harvesting and transport of maize stalks and cereal straw using both baling harvesting system (HS-A) and self-loading harvesting system (HS-B).

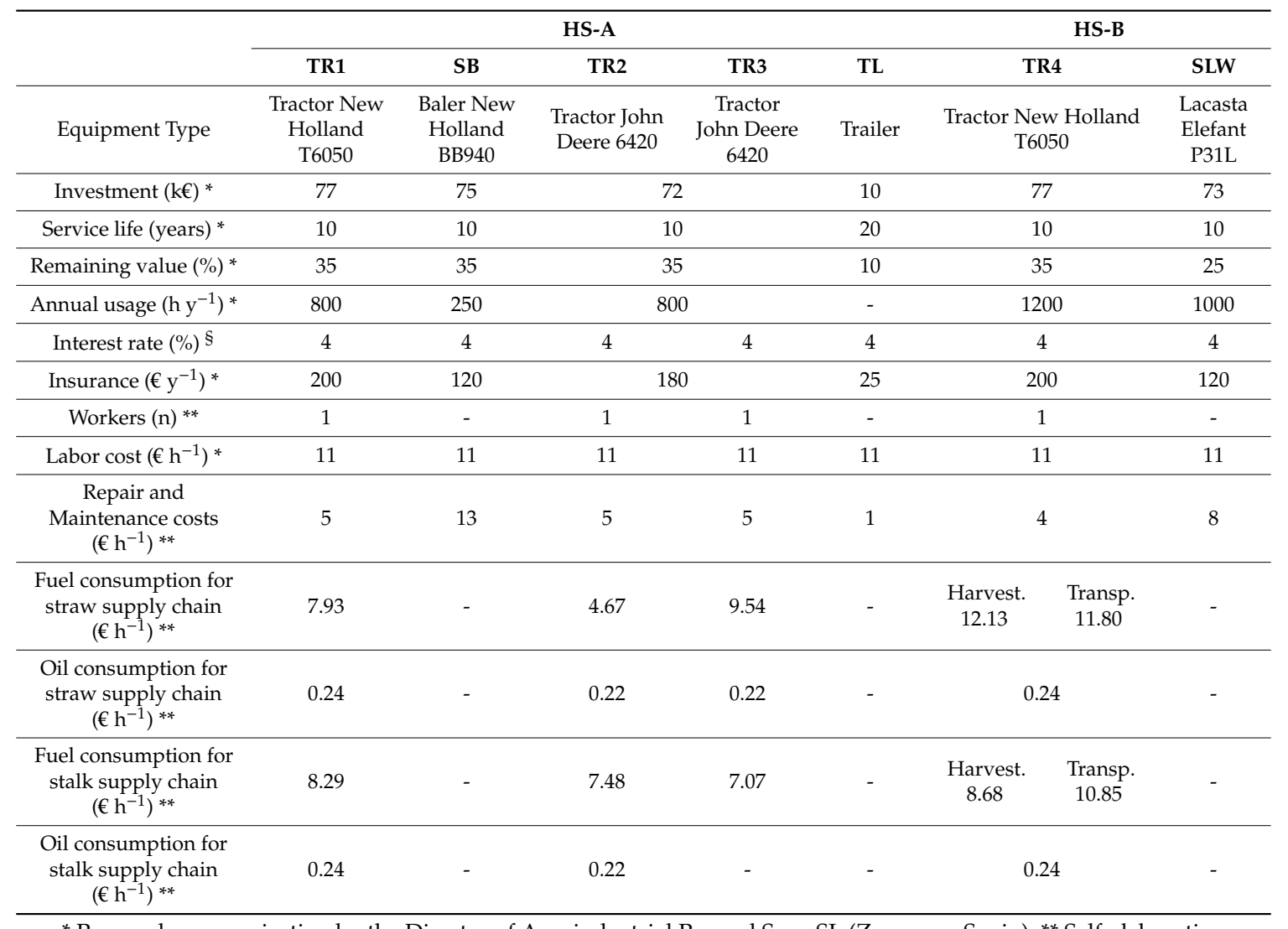

${ }^{*}$ Personal communication by the Director of Agroindustrial Pascual Sanz SL (Zaragoza, Spain); ${ }^{* *}$ Self-elaboration by primary data. $\$$ (Assirelli and Pignedoli, 2005).

The unitary costs per tons ( $€ \mathrm{Mg}^{-1}$ ) of biomass transported per $\mathrm{km}$ for the HS-A (baled biomass) was calculated according to the following formula:

$$
\mathrm{T}_{c a}=\frac{\mathrm{H}_{c}}{\mathrm{~V} \times \mathrm{L}_{c}}
$$

where:

$\mathrm{T}_{c a}=$ Unitary transport costs $\left(€ \mathrm{Mg}^{-1} \mathrm{~km}^{-1}\right)$ for the harvesting system " $\mathrm{A}$ ";

$\mathrm{H}_{\mathcal{c}}=$ Transport hourly cost $\left(€ \mathrm{~h}^{-1}\right)$;

$\mathrm{V}=$ Mean transport velocity $\left(\mathrm{km} \mathrm{h}^{-1}\right)$;

$\mathrm{L}_{c}=$ Mean load capacity $(\mathrm{Mg})$.

Unlike for the baling system, the self-loading wagon must unload the biomass every time that is completely full. According to ASAE methodology [26] the transport timing to unload the residue to the storage center represents time lost for harvested material handling, and it is unproductive time. Since, the transport timing for the HS-B increases proportionally to the distance that there is between the field to the storage center, it negatively influences the effective field capacity $\left(\mathrm{ha}^{-1}\right)$ of the harvesting system. Therefore, the calculation of the unitary transport cost for the HS-B was made by separating the time lost for transporting the biomass to the storage center from the time used for calculating the effective field capacity of the system, according to the following formula:

$$
\mathrm{T}_{c b}=\mathrm{H}_{c} \times \frac{\mathrm{h}_{t}}{\mathrm{~S} \times \mathrm{B}_{h}}
$$


where:

$\mathrm{T}_{c b}=$ Unitary transport cost $\left(€ \mathrm{Mg}^{-1} \mathrm{~km}^{-1}\right)$ for the harvesting system " $\mathrm{B}$ ";

$\mathrm{H}_{c}=$ Transport hourly cost $\left(€ \mathrm{~h}^{-1}\right)$;

$\mathrm{h}_{t}=$ Transport timing $\left(\mathrm{h} \mathrm{km}^{-1}\right) ; \mathrm{S}=$ Harvested area (ha);

$\mathrm{B}_{h}=$ Biomass harvested per hectare $\left(\mathrm{Mg} \mathrm{ha}^{-1}\right)$.

The stalks and the straw were gathered to the same storage center located at Agroindustrial Pascual Sanz SL headquarter.

The maximum distance between the fields and the storage center from which it is more economically convenient to gather the biomass with balers instead of forage hauling equipment (self-loading wagon) was obtained calculating the system equations $y_{a}=f(x)$ and $y_{b}=f(x)$ for the HS-A and HS-B per residue type (straws and stalks). The dependent value " $y$ " is the harvesting and transport costs $\left(€ \mathrm{Mg}^{-1}\right)$, while the " $\mathrm{x}$ " value represents the distance from the field to the storage centre $(\mathrm{km})$.

\section{Results and Discussion}

\subsection{Performance of Harvesting Systems}

There were large variations in results of machine performance of the two harvesting systems, depicted in Figure 1, when different biomasses were harvested. This was certainly influenced by the different amount of residual biomass available in maize and wheat. For both maize stalks harvesting systems tested, lower operating speed and, consequently, lower field capacity were observed compared to the results obtained during the harvesting of cereal straw. However, the amount of maize stalks collectable was higher as well as the material capacities (Table 2).

Table 2. Machine performance and quality of the work of the harvesting phase.

\begin{tabular}{|c|c|c|c|c|c|c|}
\hline \multirow{2}{*}{$\begin{array}{c}\text { Biomass Type } \\
\text { Harvesting System }\end{array}$} & \multicolumn{3}{|c|}{ Maize Stalk } & \multicolumn{3}{|c|}{ Wheat Straw } \\
\hline & HS-A & HS-B & $p<0.05$ & HS-A & HS-B & $p<0.05$ \\
\hline Equipment type & SB & SLW & & SB & SLW & \\
\hline Operating speed $\left(\mathrm{m} \mathrm{s}^{-1}\right)$ & $1.28 \pm 0.06$ & $0.95 \pm 0.14$ & * & $2.19 \pm 0.18$ & $1.97 \pm 0.04$ & \\
\hline Field efficiency $(\%)$ & $85.9 \pm 2.9$ & $83.5 \pm 1.7$ & & $90.2 \pm 0.4$ & $89.7 \pm 1.3$ & \\
\hline Effective Field capacity $\left(\right.$ ha $\left.\mathrm{h}^{-1}\right)$ & $2.27 \pm 0.23$ & $1.31 \pm 0.22$ & * & $4.67 \pm 0.23$ & $4.65 \pm 0.68$ & \\
\hline Material capacity $\left(\mathrm{Mg}_{\mathrm{fm}} \mathrm{h}^{-1}\right)$ & $15.86 \pm 4.70$ & $10.81 \pm 0.49$ & * & $11.18 \pm 1.15$ & $10.76 \pm 1.75$ & \\
\hline Biomass yield $\left(\mathrm{Mg}_{\mathrm{fm}} \mathrm{ha}^{-1}\right)$ & $6.9 \pm 1.32$ & $7.4 \pm 1.19$ & & $2.39 \pm 0.20$ & $2.32 \pm 0.07$ & \\
\hline Bulk density $\left(\mathrm{kg} \mathrm{m}^{-3}\right)$ & $151.36 \pm 5.53$ & $89.33 \pm 2.31$ & * & $145.75 \pm 6.63$ & $18.56 \pm 6.46$ & * \\
\hline Losses $(\%)$ & $12.68 \pm 4.30$ & $14.68 \pm 4.68$ & & $1.19 \pm 0.42$ & $0.88 \pm 0.18$ & \\
\hline Moisture content $\left(\mathrm{w}_{\mathrm{wb}} / \mathrm{w}_{\mathrm{wb}} \%\right)$ & $13.33 \pm 0.58$ & $9.39 \pm 0.92$ & * & $6.76 \pm 1.87$ & $4.17 \pm 0.52$ & * \\
\hline
\end{tabular}

* Values marked with asterisks are significantly different $(p<0.05)$ (per parameter and residue type).

Considering maize stalks harvesting, the baling system showed higher values for all the parameters except for biomass yield and losses, while regarding wheat straw harvesting, the baler showed higher results for all the parameters compared the SLW. Statistically significant differences were found for the field capacity and material capacity of the two harvesting systems tested in maize stalks collection, while no differences were found between the same parameters for wheat straw harvesting. No statistically significant differences were observed between field efficiency, biomass yield, and losses for the two harvesting systems in both maize stalks and cereal straw. This result is important for an IBLC because both the harvesting systems permit collecting a similar amount of biomass (similar yield amount per residue type) with similar harvesting losses, not representing discriminative parameters in the decision process for the more adapt collection system. Values of moisture content showed differences statistically significant for each cereal residue as well as for bulk density and operating speed. Results highlighted that the bulk density of the baled biomass was 41.0 and $87.3 \%$ higher of the loosed biomass, for stalk and straw respectively. The bulk density of the maize stalk was $79.2 \%$ higher than for wheat straw. These values have a great influence on the transportation to the storage center. 
Corn residue is usually harvested with balers (large round bales, large square bales, or small square bales) [27]. However, self-loading wagons do not need transport trucks, and they rely on tractor power to harvest and transport. Therefore, self-loading wagons may be a viable method to reduce biomass harvest fuel and labor costs where transport distance is short [28]. Lizotte $(2011,2013)$ carried out corn stover harvesting tests using self-loading wagon and round baler (RB) collecting $1.44 \mathrm{Mg}_{\mathrm{dm} \mathrm{ha}} \mathrm{ha}^{-1}$ $\left(1.57 \mathrm{Mg}_{\mathrm{fm}} \mathrm{ha}^{-1}\right.$; moisture content of $\left.8 \%\right)$ and $1.85 \mathrm{Mg}_{\mathrm{dm}} \mathrm{ha}^{-1}\left(1.98 \mathrm{Mg}_{\mathrm{fm}} \mathrm{ha}^{-1}\right.$; moisture content of $6.8 \%$ ) with a RB and a SLW, respectively. The lowest biomass available in the experimental field of Lizotte $(2011,2013)$ permitted to work faster than the equipment used during our tests, so the field capacity of the round baler resulted $3.8 \mathrm{ha} \mathrm{h}^{-1}$ going at a work speed of $5 \mathrm{~km} \mathrm{~h}^{-1}[29,30]$. Similarly, our results showed a field capacity of the SLW variable due to the travel distance from the field to the IBLC. Lizotte and Savoie (2013) observed that SLW allowed high field speed that resulted in $10.9 \mathrm{~km} \mathrm{~h}^{-1}$ [30]. In our test, the maximum field speed achieved by the SLW was $3.94 \mathrm{~km} \mathrm{~h}^{-1}$.

It is clear how the amount of biomass available influences the work speed and so the field capacity of the equipment. In fact, the field capacities of SLW and SB when wheat straw is collected resulted double compared with maize stalk collection due to the smaller quantity of residues to be processed by the machines.

Wheat straw is usually collected by balers, but according to Brownell (2012) the self-loading wagon uses considerably less energy and labor than the traditional forage harvesting system [28].

It should be highlighted that while the baler can harvest the biomass independently from the bale-handling operation that can be performed by another tractor with fork, the self-loading wagon must discharge the biomass to the IBLC or an intermedium storage area every time that the wagon is completely full. Therefore, considering the time required to transport and discharge the biomass, the field capacity of the self-loading wagon decreases as the distance from the field to the storage area increases (Figure 2). This aspect has an important influence on the selection of harvesting system.

As it is possible to see from Figure 2, in the case of straw harvesting by system " $B$ ", in the first $5 \mathrm{~km}$ of distance between field and IBLC, the field capacity of the SLW passed from $4.05 \mathrm{ha} \mathrm{h}^{-1}$ (biomass unloaded directly in the field) to $2.05 \mathrm{ha} \mathrm{h}^{-1}$. In other words, the harvesting of wheat straw with SLW considering a transport distance of $5 \mathrm{~km}$ involves a reduction of almost $50 \%$ of the field capacity if compared with the unloading of the biomass directly on the field. A transport distance of $50 \mathrm{~km}$ is equivalent to a loss of field capacity of $91 \%$ compared to the discharge of biomass on the field $\left(0.38 \mathrm{ha} \mathrm{h}^{-1}\right)$. In the case of maize stalk, the field capacity of the SLW is halved at a distance of $8 \mathrm{~km}$ between the field and the IBLC, passing from $1.31 \mathrm{ha} \mathrm{h}^{-1}$ to $0.66 \mathrm{ha} \mathrm{h}^{-1}$, respectively.

In general, the field capacity of the harvesting system "B" with SLW for both agricultural residues was halved within the first few kilometers distance from the field to the IBLC, and in particular, at a distance of $10 \mathrm{~km}$, there were reductions in the field capacity of $66 \%$ and $55 \%$ for wheat straw and maize stalks harvesting systems, respectively (Figure 2).

The study focused on evaluating the system that best suits the real needs of a Spanish company that will use the residual biomass to produce energy, starting from the equipment normally uses for IBLC business.

However, the implementation of a model to determine the number of vehicles that would be needed to ensure a continuous harvest as, for example, proposed by Brownell 2012, will be important for future analysis.

Fuel consumption is a key result in Table 3. The fuel consumption per area unit for straw harvesting resulted generally lower than the harvesting of corn stalks. This is essentially because the residues harvested in the wheat field were smaller, and therefore, the machines processed less material than in the maize field. Even if the fuel consumption of the only harvesting phase was higher for the self-loading wagon respect to the tractor with baler, considering also the consumption of the bales uploading phase, no statistically significant differences were found between the two harvesting systems for each cereal residue per area unit $\left(\mathrm{L} \mathrm{ha}^{-1}\right)$. On the other hand, comparison of the hourly fuel consumption of the maize stalks harvest with the two methods was statistically significant, contrary 
to what was observed for straw (Table 3 and Figure 3). Straw baling and loading bales together consumed a quantity of fuel similar to the self-loading wagon (Figure 3). The harvesting of straw with a self-loading wagon at high speed resulted in higher consumption compared to what was measured during the harvesting of the corn stalks. However, the differences in fuel consumption obtained from the individual comparison of the harvesting stages of maize stalks and wheat straw (e.g., SLW maize stalk vs. SLW cereal straw) were always statistically not significant.

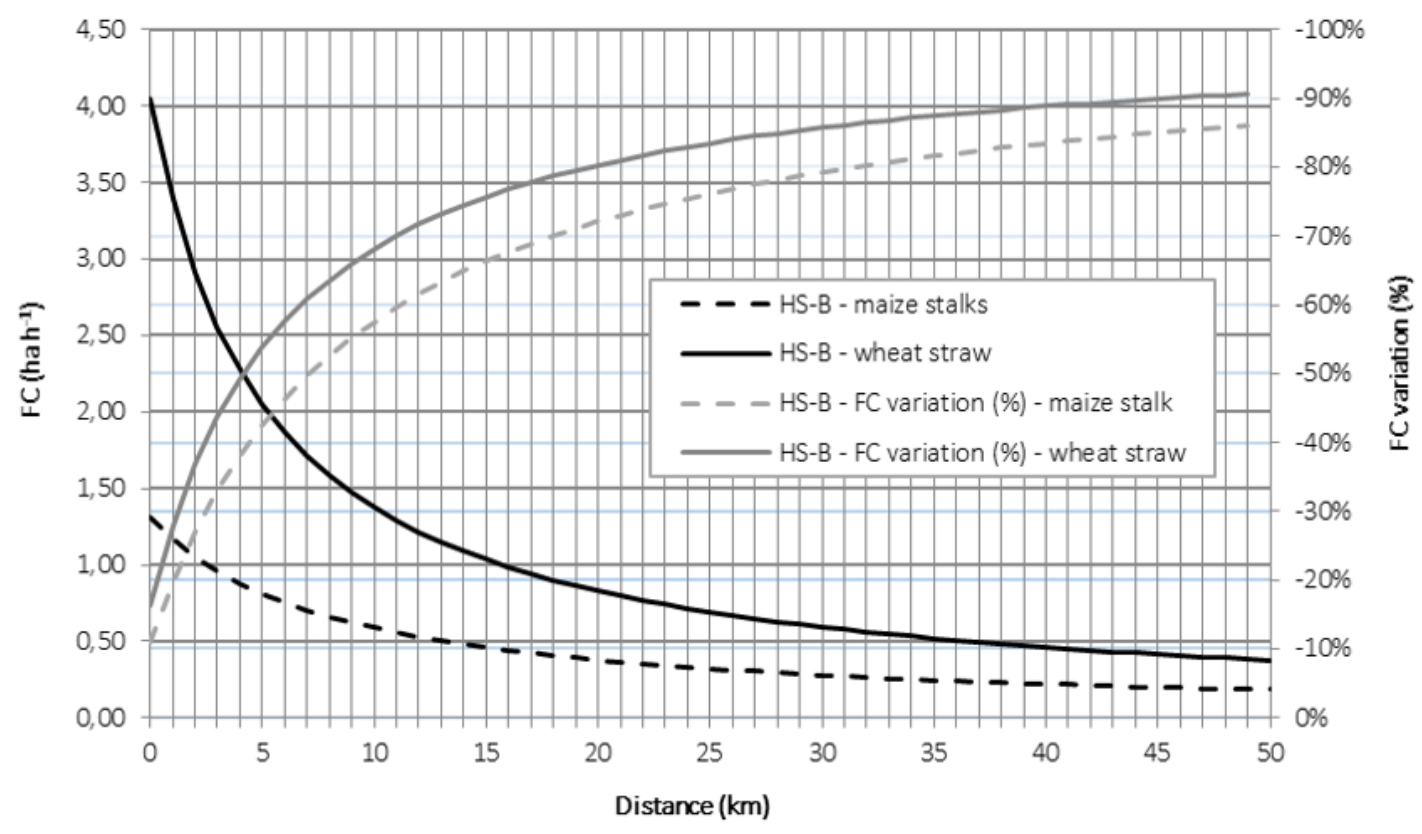

Figure 2. Trend in field capacity (FC) of the harvesting system "B" (HS-B) and its percentage variation in relation to transport distance for both wheat straw and maize stalks.

The comparison of the fuel consumed per product unit for both the maize stalks and cereal straw harvest with the two harvesting methods resulted not statically significant as well.

The transport of the product to the IBLC by SLW showed the highest hourly consumption. The transport of cereal straw with SLW showed an increase in fuel consumption of $22.9 \%$ compared to the tractor with bale trailer. In the case of the transport of maize stalks via SLW, the fuel consumption was even 52.5\% higher (Table 3 and Figure 3).

Table 3. Consumption measured during harvesting and transport of maize stalks and wheat straw.

\begin{tabular}{|c|c|c|c|c|c|c|}
\hline \multirow{2}{*}{$\begin{array}{c}\text { Biomass Type } \\
\text { Harvesting System }\end{array}$} & \multicolumn{3}{|c|}{ Maize Stalk } & \multicolumn{3}{|c|}{ Wheat Straw } \\
\hline & HS-A & HS-B & $p<0.05$ & HS-A & HS-B & $p<0.05$ \\
\hline \multicolumn{7}{|l|}{$\begin{array}{l}\text { Fuel consumption per } \\
\text { area unit }\end{array}$} \\
\hline Harvesting $\left(1 \mathrm{ha}^{-1}\right)$ & $6.42( \pm 1.05)$ & $9.42( \pm 1.12)$ & & $2.96( \pm 0.44)$ & $4.59( \pm 0.88)$ & \\
\hline Bales loading $\left(1 \mathrm{ha}^{-1}\right)$ & $5.44( \pm 1.63)$ & $\mathrm{n} / \mathrm{a}$ & & $1.43( \pm 0.19)$ & $\mathrm{n} / \mathrm{a}$ & \\
\hline \multicolumn{7}{|l|}{$\begin{array}{l}\text { Fuel consumption per } \\
\text { product unit }\end{array}$} \\
\hline Harvesting $\left(\mathrm{l} \mathrm{t}^{-1}\right)$ & $0.97( \pm 0.31)$ & $1.40( \pm 0.37)$ & & $1.25( \pm 0.28)$ & $1.97( \pm 0.35)$ & \\
\hline Bales loading $\left(1 \mathrm{t}^{-1}\right)$ & $0.83( \pm 0.36)$ & $\mathrm{n} / \mathrm{a}$ & & $0.60( \pm 0.12)$ & $\mathrm{n} / \mathrm{a}$ & \\
\hline \multicolumn{7}{|l|}{$\begin{array}{l}\text { Fuel consumption per } \\
\text { hourly time }\end{array}$} \\
\hline Harvesting $\left(1 \mathrm{~h}^{-1}\right)$ & $14.45( \pm 1.37)$ & $15.13( \pm 3.09)$ & $*$ & $13.82( \pm 2.05)$ & $21.14( \pm 3.69)$ & \\
\hline Bales loading $\left(1 \mathrm{~h}^{-1}\right)$ & $13.03( \pm 4.47)$ & $\mathrm{n} / \mathrm{a}$ & * & $8.14( \pm 1.95)$ & $\mathrm{n} / \mathrm{a}$ & \\
\hline Transport $\left(1 \mathrm{~h}^{-1}\right)$ & $12.40( \pm 0.91)$ & $18.91( \pm 2.47)$ & & $16.73( \pm 1.74)$ & $20.56( \pm 1.04)$ & \\
\hline
\end{tabular}

*Values marked with asterisks are significantly different $(p<0.05)$ (per parameter per residue type). 


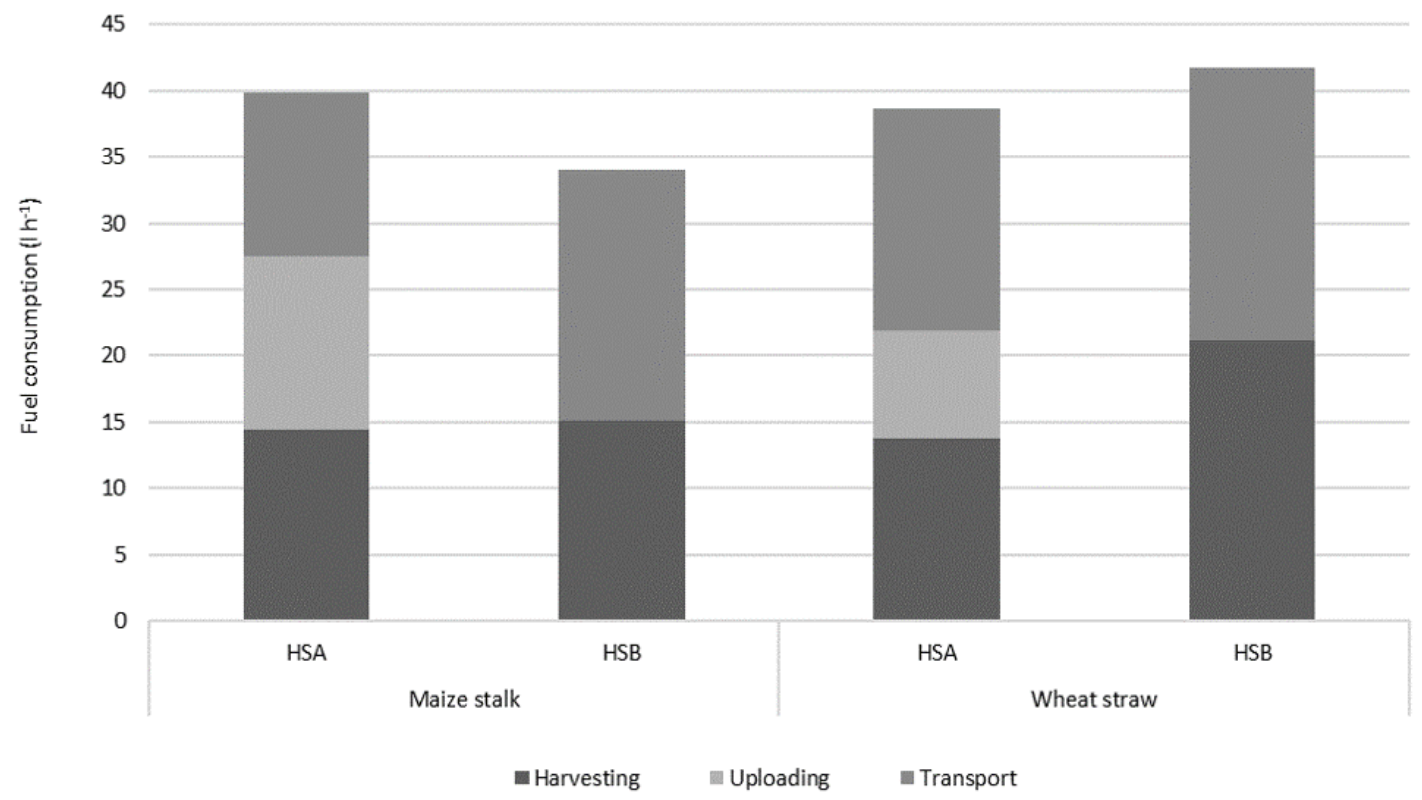

Figure 3. Fuel consumption of the harvesting system " $A$ " (HS-A) and harvesting system "B" (HS-B) for wheat straw and maize stalks.

\subsection{Cost Analysis}

The cost analysis highlighted that the baling system (HS-A) is more expensive than the harvesting system based to the self-loading wagon (HS-B) (Table 4). In particular, the total hourly cost and the unitary cost of the HS-B to collect maize stalk were $57 \%$ and $54 \%$ lower than the cost for the HS-A, respectively. Wheat straw harvesting with HS-B presented a total hourly cost and the unitary cost of $53 \%$ and $42 \%$ higher than the cost of the HS-A, respectively. Variable costs in all cases had the greatest impact on total hourly cost (about $65 \%$ ), reaching values of more than $70 \%$ for straw collection with HS-B.

Table 4. Cost analysis of the harvesting system " $\mathrm{A}$ " (HS-A) and harvesting system " $\mathrm{B}$ " (HS-B) for wheat straw and maize stalks.

\begin{tabular}{|c|c|c|c|c|c|c|}
\hline & \multicolumn{4}{|c|}{ Harvesting System "A" } & \multicolumn{2}{|c|}{ Harvesting System "B" } \\
\hline & Baling & Uploading & Total Harvesting & Transport & SLW & Transport \\
\hline Financial costs $(€)$ & 152,000 & 72,000 & 224,000 & 82,000 & \multicolumn{2}{|c|}{150,000} \\
\hline \multicolumn{7}{|l|}{ Wheat straw } \\
\hline Fixed costs $\left(€ \mathrm{~h}^{-1}\right)$ & 37.7 & 8.6 & 46.3 & 13.7 & \multicolumn{2}{|c|}{13.7} \\
\hline Variable costs $\left(€ \mathrm{~h}^{-1}\right)$ & 36.7 & 20.6 & 57.3 & 26.5 & 35.5 & 35.1 \\
\hline Total hourly costs $\left(€ \mathrm{~h}^{-1}\right)$ & 74.4 & 29.2 & 103.6 & 40.2 & 49.1 & 48.8 \\
\hline Unitary costs $\left(€ \mathrm{Mg}^{-1}\right)$ & 6.6 & 2.4 & 9.0 & $0.34 *$ & 5.23 & 1.02 \\
\hline \multicolumn{7}{|l|}{ Maize stalks } \\
\hline Fixed costs $\left(€ \mathrm{~h}^{-1}\right)$ & 37.7 & 8.6 & 46.3 & 13.7 & \multicolumn{2}{|c|}{13.7} \\
\hline Variable costs $\left(€ \mathrm{~h}^{-1}\right)$ & 37.0 & 23.4 & 60.4 & 24.0 & 32.0 & 34.2 \\
\hline Total hourly costs $\left(€ \mathrm{~h}^{-1}\right)$ & 74.7 & 32.0 & 106.7 & 37.7 & 45.7 & 47.8 \\
\hline Unitary costs $\left(€ \mathrm{Mg}^{-1}\right)$ & 6.7 & 2.6 & 9.3 & $0.32 * *$ & 4.24 & 0.61 \\
\hline
\end{tabular}

* round trip cost $€ \mathrm{Mg}^{-1} \mathrm{~km}^{-1}$ considering a measured average speed of $18.2 \mathrm{~km} \mathrm{~h}^{-1}$ and an average load of $6.5 \mathrm{t}$ of wheat straw bales transported per trip. ${ }^{* *}$ round trip cost $€ \mathrm{Mg}^{-1} \mathrm{~km}^{-1}$ considering a measured average speed of $22.9 \mathrm{~km} \mathrm{~h}^{-1}$ and an average load of $5.1 \mathrm{t}$ of maize stalk bales transported per trip.

Furthermore, maize stalks harvesting phase with the HS-A resulted more expensive than wheat straw harvesting with HS-A of almost $3 \%$.

The study showed that the most suitable system for collecting cereal and corn residues is the self-loading wagon if the transport of the biomass to IBLC is not included. 
The transportation completely influences the final cost of the residue, and the transport method should be chosen carefully. The dynamic simulation of straw harvesting systems based on conventional high-density bales carried out by Nilsson (2000) demonstrated that longer transport distances and lower straw yields per hectare $\left(<4 \mathrm{Mg} \mathrm{ha}^{-1}\right)$ were the main reasons for the higher costs of straw handling in Sweden [31]. According to our results, bales transport resulted more chip than using the SLW in Spain. The cost to harvest and transport the maize stalks resulted $9.62 € \mathrm{Mg}^{-1}$ using the HS-A and $4.85 € \mathrm{Mg}^{-1}$ using the HS-B, with a transport cost of 0.32 and $0.61 € \mathrm{Mg}^{-1} \mathrm{~km}^{-1}$, respectively (Table 4). The wheat straw transport costs resulted slightly higher than stalks reaching values of $1.02 € \mathrm{Mg}^{-1} \mathrm{~km}^{-1}$ if the self-loading wagon is used for the transportation of the straw to the IBLC.

According to Brownell (2012), the wagon system is efficient when harvesting dry biomass within $8 \mathrm{~km}$ travel distance. For longer distances, a large square baler might be a better option as it can produce 63 large square bales of straw every hour, equal to almost $16 \mathrm{Mg} \mathrm{h}^{-1}$ at $13 \%$ of moisture content, in line with Kemmerer (2011) that obtained a material capacity of $13 \mathrm{Mg} \mathrm{h}^{-1}$ of wet mass [32].

Figure 4 depicts the maximum distance to the IBLC from which it is more economically convenient to gather the biomass in bales instead of using a self-loading wagon per each residue type. According to our results, the transition distance has been identified in $11.4 \mathrm{~km}$ and $16.0 \mathrm{~km}$, with a total harvesting and transport cost of $15.8 € \mathrm{Mg}^{-1} \mathrm{~km}^{-1}$ and $14.1 € \mathrm{Mg}^{-1} \mathrm{~km}^{-1}$, for wheat straw and maize stalk respectively. The higher bulk density of loose maize stalks compared to straw $\left(89.3 \mathrm{~kg} \mathrm{~m}^{-3}\right.$ and $18.6 \mathrm{~kg} \mathrm{~m}^{-3}$, respectively) has had a significant influence on the results of the economic distances to gather the residual biomass of stalk and straw.
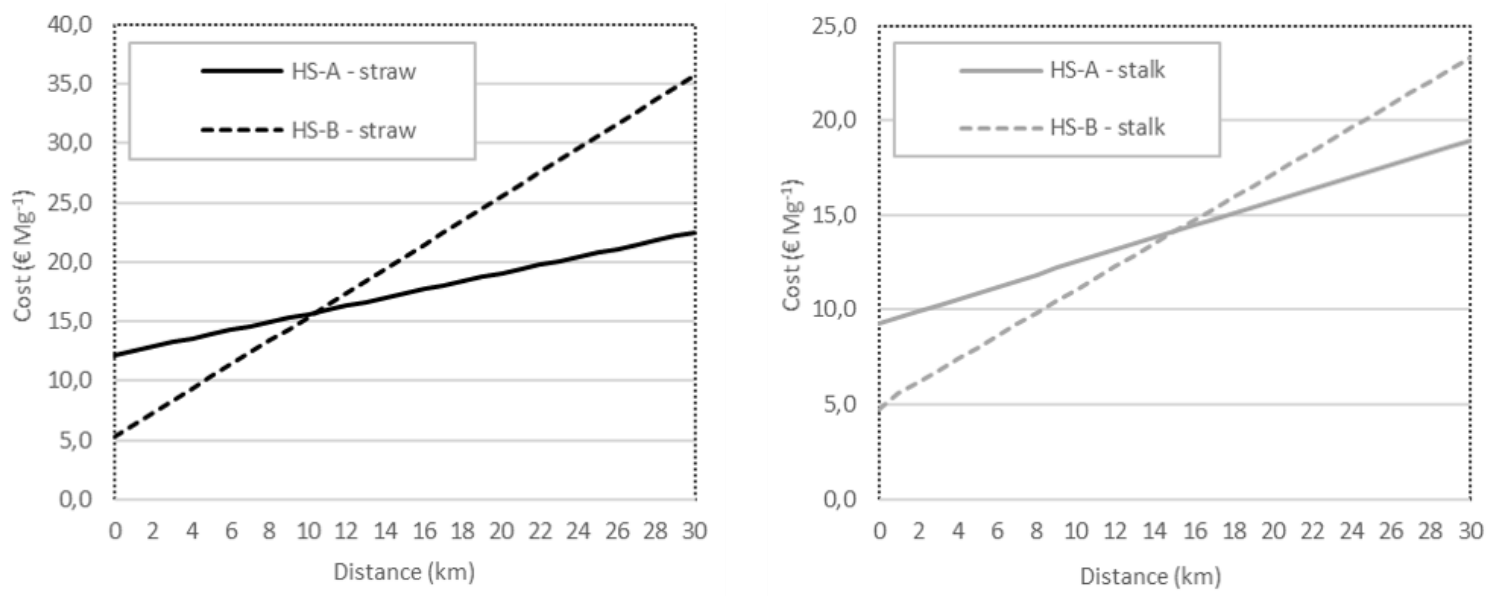

Figure 4. Economic thresholds of the transport of wheat straw and maize stalks by the use of harvesting system "A" (HS-A) and harvesting system "B" (HS-B) in Spain.

As observed by Lizotte (2014) final packaging format (rectangular bales, round bales, chopped bulk material) also plays an important role on storage costs and for this reason this is another aspect that should be consider in future analysis [33].

Furthermore, according to Khan Mubeen (2012) crops grow by utilizing the minerals from soil. When crops are harvested the mineral contents of the soil are also lost, and thus the supplementation of synthetic fertilizers is required [34,35]. Moreover, only a certain number of tons can safely be removed per hectare per year, to avoid erosion phenomenon and fertility reduction effects. For this reason, even if this aspect was not analyzed in this study, in addition to the direct costs incurred in collecting, handling, and hauling the stalks and straw, farmers will expect compensation for the nutrients removed, and this aspect should be included as well for the evaluation of the sustainability of the supply chain of residues. 


\section{Conclusions}

Corn stalks and wheat straw are less costly than growing a dedicated energy crop because they are produced as a co-product of grain production, and no additional cost, other than the harvest and nutrient replacement, is required to produce the residues. However, estimating the cost of harvesting residues is not straightforward and depends on which harvest methods are used, the equipment, the amount of biomass removed per hectare, and the storage and transportation method.

The scope of this research was to evaluate the cost of logistics in the harvest of cereal straw and maize stalks, considering two harvest systems (baling vs. self-loading wagon). According to the parameters analyzed, the use of the self-loading forage wagon resulted more convenient for both wheat straw and maize stalks up to a distance of $11.4 \mathrm{~km}$ and $16.0 \mathrm{~km}$, respectively, from the delivery point; after this threshold, it results more convenient the use of balers and trucks for bale transport. As the parameters utilized in this study were specific, results should be interpreted taking into account that the variation of one parameter can influence the final results. However, in general terms, the study fully demonstrated that when considering short distances from logistic centers the use of self-loading wagons should be preferred to the baling, and vice versa for longer distances, the densification in bales will be more effective in economic terms.

It is important to conclude this paper stressing that in the selection of the harvest systems another important aspect is the storage. This will require deeper attention in the future as storage of biomass can determine economic losses or additional costs due to reasons such as the degradation of the dry matter, the need of covering systems, and space availability. Further studies will be performed to evaluate storage dynamics and related-costs in a way to provide a complete analysis of the wheat straw and maize stalk logistics.

Aspects related to cost estimation of storage and nutrients to be returned to the soil and the damage due to possible erosion phenomena related to the removal of residues should be investigated and included in future studies.

Author Contributions: Data curation, A.S. (Alessandro Suardi), S.B., V.A. and A.S. (Antonio Scarfone); Funding acquisition, L.P.; Investigation, A.S. (Alessandro Suardi), S.B., V.A. and A.S. (Antonio Scarfone); Methodology, A.S. (Alessandro Suardi), S.B., V.A. and A.S. (Antonio Scarfone); Project administration, L.P.; Writing-original draft, A.S. (Alessandro Suardi), S.B., V.A. and A.S. (Antonio Scarfone).

Funding: This project has received funding from the European Union's Horizon 2020 research and innovation programme under Grant Agreement No 727961.

Acknowledgments: The work was performed in the framework of the European project AGROinLOG "Demonstration of innovative integrated biomass logistics centres for the Agro-industry sector in Europe". The authors wish to thank the employees of Agroindustrial Pascual Sanz firm (Zaragoza, Spain) for the authorization to conduct the tests and for their assistance in performing them and their professionality and availability.

Conflicts of Interest: The authors declare no conflicts of interest.

\section{References}

1. Scarlat, N.; Dallemand, J.F.; Banja, M. Possible impact of 2020 bioenergy targets on European Union land use. A scenario-based assessment from national renewable energy action plans proposals. Renew. Sustain. Energy Rev. 2013, 18, 595-606. [CrossRef]

2. Buratti, C.; Barbanera, M.; Fantozzi, F. A comparison of the European renewable energy directive default emission values with actual values from operating biodiesel facilities for sunflower, rape and soya oil seeds in Italy. Biomass Bioenergy 2012, 47, 26-36. [CrossRef]

3. Sathre, R. Comparing the heat of combustion of fossil fuels to the heat accumulated by their lifecycle greenhouse gases. Fuel 2014, 115, 674-677. [CrossRef]

4. Ghaderi, H.; Pishvaee, M.S.; Moini, A. Biomass supply chain network design: An optimization-oriented review and analysis. Ind. Crops Prod. 2016, 94, 972-1000. [CrossRef]

5. Lal, R. World crop residues production and implications of its use as a biofuel. Environ. Int. 2005, 31, 575-584. [CrossRef] [PubMed] 
6. Scarlat, N.; Martinov, M.; Dallemand, J.F. Assessment of the availability of agricultural crop residues in the European Union: Potential and limitations for bioenergy use. Waste Manag. 2010, 30, 1889-1897. [CrossRef] [PubMed]

7. Blanco-Canqui, H. Crop residue removal for bioenergy reduces soil carbon pools: How can we offset carbon losses? Bioenergy Res. 2013, 6, 358-371. [CrossRef]

8. Eleki, K.; Cruse, R.M.; Rogovska, N.; Fodor, L.; Szabó, L. Soil and crop management and biomass removal effects on soil organic matter content in Hungary. Stud. Agric. Econ. 2014, 116, 107-113. [CrossRef]

9. Nelson, R.G. Resource assessment and removal analysis for corn stover and wheat straw in the Eastern and Midwestern United States-Rainfall and wind-induced soil erosion methodology. Biomass Bioenergy 2002, 22, 349-363. [CrossRef]

10. Ericsson, K.; Nilsson, L.J. Assessment of the potential biomass supply in Europe using a resource-focused approach. Biomass Bioenergy 2006, 30, 1-15. [CrossRef]

11. Johnson, J.F.; Allmaras, R.R.; Reicosky, D.C. Estimating source carbon from crop residues, roots and rhizodeposits using the national grain-yield database. Agron. J. 2006, 98, 622-636. [CrossRef]

12. Wilhelm, W.W.; Johnson, J.M.F.; Hatfield, J.L.; Voorhees, W.B.; Linden, D.R. Crop and soil productivity response to corn residue removal. Agron. J. 2004, 96, 1-17. [CrossRef]

13. Iakovou, E.; Karagiannidis, A.; Vlachos, D.; Toka, A.; Malamakis, A. Waste biomass-to-energy supply chain management: A critical synthesis. Waste Manag. 2010, 30, 1860-1870. [CrossRef] [PubMed]

14. Yazan, D.M.; van Duren, I.; Mes, M.; Kersten, S.; Clancy, J.; Zijm, H. Design of sustainable second-generation biomass supply chains. Biomass Bioenergy 2016, 94, 173-186. [CrossRef]

15. Carriquiry, M.A.; Du, X.; Timilsina, G.R. Second generation biofuels: Economics and policies. Energy Policy 2011, 39, 4222-4234. [CrossRef]

16. Blanco-Canqui, H.; Lal, R. Soil and crop response to harvesting corn residues for biofuel production. Geoderma 2007, 141, 355-362. [CrossRef]

17. Kretschmer, B.; Allen, B.; Hart, K. Mobilising Cereal Straw in the EU to Feed Advanced Biofuel Production; Institute for European Environmental Policy: London, UK, 2012.

18. Kadam, K.L.; McMillan, J.D. Availability of corn stover as a sustainable feedstock for bioethanol production. Bioresour. Technol. 2003, 88, 17-25. [CrossRef]

19. AGROinLOG Demonstration of Integrated Biomass Logistic Centres (IBLC) for Food and Non-Food Products. Available online: http://agroinlog-h2020.eu/en/home/ (accessed on 25 May 2018).

20. Onofri, A. Routine statistical analyses of field experiments by using an Excel extension. In Proceedings of the 6th National Conference of the Italian Biometric Society, Pisa, Italy, 20-22 June 2007; Volume 2022.

21. Assirelli, A.; Croce, S.; Acampora, A.; Civitarese, V.; Suardi, A.; Santangelo, E.; Pari, L. An innovative system for conditioning biomass sorghum [Sorghum bicolor (L.) Moench]. Trans. ASABE 2013, 56, 829-837.

22. Pari, L.; Suardi, A.; del Giudice, A.; Scarfone, A.; Santangelo, E. Influence of chipping system on chipper performance and wood chip particle size obtained from peach prunings. Biomass Bioenergy 2018, 112, 121-127. [CrossRef]

23. International Organization for Standardization. Solid Biofuels—Determination of Moisture Content-Oven Dry Method_Part 2: Total Moisture—Simplified Method; Tehnical Report EN ISO 18134-2:2017; International Organization for Standardization: Geneva, Switzeland, 2017.

24. International Organization for Standardization. Solid Biofuels_Determination of Bulk Density; Tehnical Report No. ISO 17828:2015; International Organization for Standardization: Geneva, Switzerland, 2015; p. 8.

25. Assirelli, A.; Pignedoli, S. Costo di esercizio delle macchine agricole. Centro Ricerche e Produzione Animale 2005, 5, 1-10.

26. ASAE. Agricultural Machinery Management; Tehnical Report No. ASAE EP496.2; ASAE Stand: Washington, DC, USA, 2000; pp. 344-349.

27. Edwards, W. Estimating a Value for Corn Stover. 2007. Available online: https://www.extension.iastate.edu/ AGDm/crops/pdf/a1-70.pdf (accessed on 7 August 2019).

28. Brownell, D.K.; Liu, J.; Hilton, J.W.; Richard, T.L.; Cauffman, G.R.; Macafee, B.R. Evaluation of two forage harvesting systems for herbaceous biomass harvesting. Trans. ASABE 2012, 55, 1651-1658. [CrossRef]

29. Lizotte, P.L.; Savoie, P. Harvesting residual corn stover with a self-loading wagon for animal bedding. In Proceedings of the 2011 American Society of Agricultural and Biological Engineers, Louisville, KY, USA, 7-10 August 2011; p. 1. 
30. Lizotte, P.L.; Savoie, P. Spring harvest of corn stover for animal bedding with a self-loading wagon. Appl. Eng. Agric. 2013, 29, 25-31. [CrossRef]

31. Nilsson, D. Dynamic simulation of straw harvesting systems: Influence of climatic, geographical and biological factors on performance and costs. J. Agric. Eng. Res. 2000, 76, 27-36. [CrossRef]

32. Kemmerer, B.D.; Liu, J. Comparison of large square bale handling options. In Proceedings of the 2011 American Society of Agricultural and Biological Engineers, Louisville, KY, USA, 7-10 August 2011; p. 1.

33. Lizotte, P.L.; Savoie, P.; Khelifi, M. Cost Analysis of corn stover harvested in the spring. In Proceedings of the 2014 American Society of Agricultural and Biological Engineers, Montreal, QC, Canada, 13-16 July 2014; p. 1.

34. Johnson, J.M.F.; Wilhelm, W.W.; Karlen, D.L.; Archer, D.W.; Wienhold, B.; Lightle, D.T.; Laird, D.; Baker, J.; Ochsner, T.E.; Novak, J.M. Nutrient removal as a function of corn stover cutting height and cob harvest. Bioenergy Res. 2010, 3, 342-352. [CrossRef]

35. Khan, T.S.; Mubeen, U. Wheat straw: A pragmatic overview. Curr. Res. J. Biol. Sci. 2012, 4, 673-675.

(C) 2019 by the authors. Licensee MDPI, Basel, Switzerland. This article is an open access article distributed under the terms and conditions of the Creative Commons Attribution (CC BY) license (http://creativecommons.org/licenses/by/4.0/). 